\title{
OJS

\section{O ENSINO HÍBRIDO NO CONTEXTO DA PANDEMIA: DILEMAS E PERSPECTIVAS NO ENSINO E NAS AULAS DE GEOGRAFIA}

\author{
Nayara Barreto da Costa ${ }^{1}$, José Marcelo Lopes Júnior ${ }^{2}$, Fernando Barros da Silva ${ }^{3}$, \\ Laura das Chagas Melo ${ }^{4}$
}

\begin{abstract}
${ }^{1}$ Licenciada em Geografia e mestranda em Geografia pela Universidade Federal de Alagoas (UFAL), nayara.costa@igdema.ufal.br, ORCID iD: https://orcid.org/0000-0002-0751-1941.

${ }^{2}$ Graduado em Meteorologia e doutorando em Meteorologia pelo Instituto Nacional de Pesquisas Espaciais (INPE), josemarcelolopesjunior@ hotmail.com, ORCID iD: https://orcid.org/0000-0001-5744-2561.

${ }^{3}$ Graduando em Ciências Biológicas - licenciatura pela Universidade Federal de Alagoas, fernando.silva@icbs.ufal.br, ORCID iD: https://orcid.org/0000-0002-1230-1500.

${ }^{4}$ Graduada em Química - licenciatura pela Universidade Federal de Alagoas, laurachagas592@hotmail.com, ORCID iD: https://orcid.org/0000-0003-3431-8634.
\end{abstract}

Artigo recebido em 14/05/2021 e aceito em 10/07/2021

\section{RESUMO}

O presente trabalho objetiva-se investigar os impasses e as perspectivas do ensino e das aulas de Geografia na modalidade híbrida de ensino no cenário pandêmico atual. Para tanto, foi realizada uma revisão bibliográfica relacionada aos desafios de empregar o saber cientifico nas aulas remotas e as dificuldades relativas ao ensino híbrido em tempos de pandemia, assim como para complementar o estudo de caso no qual foram avaliados pontos relativos ao ensino supracitado nas aulas de Geografia no período de fevereiro a março de 2021 numa escola privada de ensino básico. Os dados referentes ao estudo de caso foram descritos na forma de relato de experiência. A condução eficiente do ensino de Geografia sempre apresentou dificuldades, e nas análises feitas durante as aulas dessa ciência destacam-se a falta de recursos suficientes para se trabalhar a ciência geográfica nas turmas do ensino fundamental, além da dificuldade de acompanhar os estudantes que assistiam as aulas de forma remota, principalmente na articulação das atividades que eram aplicadas. Todavia, o cenário atual é sugestivo à ciência geográfica, o que foi possível visualizar, sobretudo, nas aulas ministradas na turma do $9^{\circ}$ ano, a qual teve participação ativa nas discussões orientadas pela professora, por meio da ministração do conteúdo acerca da Globalização e as suas interpretações. Considera-se que apesar das inúmeras dificuldades enfrentadas nas aulas de Geografia na forma híbrida de ensino no presente cenário, este possibilitou a sua problematização, contribuindo para o conhecimento crítico e reflexivo acerca do meio por parte dos estudantes.

Palavras-chave: Educação Geográfica. Dificuldades. Possibilidades. Aprendizagem. COVID-19. 


\title{
HYBRID TEACHING IN THE CONTEXT OF PANDEMIA: DILEMMS AND PERSPECTIVES IN TEACHING AND GEOGRAPHY CLASSES
}

\begin{abstract}
The present paper aims to investigate the impasses and perspectives of teaching and Geography classes in the hybrid teaching modality in the current pandemic scenario. A bibliographic review was carried out related to the challenges of using scientific knowledge in remote classes and the difficulties related to hybrid teaching during the pandemic, also to complement the case study in which points related to aforementioned teaching were evaluated in Geography classes from February to March 2021 in a private elementary school. The data referring to the case study were described in form of experience report. Conducting Geography teaching efficiently has always presented difficulties, and in the analyzes made during this science classes was observed the lack of sufficient resources to work on geographic science in elementary school classes, in addition to the difficulty of accompanying the students who were watching the class remotely, mainly in articulating of the activities that were applied. However, the current scenario is suggestive of geographic science, which was possible to see, above all, in the classes taught in the 9th grade class, which had an active participation in the discussions guided by the teacher, through the teaching of content about Globalization and their interpretations. It is considered that despite the numerous difficulties faced in Geography classes in the hybrid form of teaching in the present scenario, it allow its problematization, contributing to the critical and reflective knowledge about the environment by the students.
\end{abstract}

Keywords: Geographic Education. Difficulties. Possibilities. Learning. COVID-19.

\section{LA ENSEÑANZA HÍBRIDA EN EL CONTEXTO DE LA PANDEMIA: DILEMAS Y PERSPECTIVAS EN LAS CLASES DE ENSEÑANZA Y GEOGRAFÍA}

\section{RESUMEN}

El presente trabajo tiene como objetivo investigar los impases y las perspectivas de la enseñanza y las clases de Geografía en la modalidad de enseñanza híbrida en el escenario actual de la pandemia. Con este fin, se realizó una revisión bibliográfica relacionada con los retos de emplear el conocimiento científico en las clases a distancia y las dificultades relacionadas con la enseñanza híbrida en tiempos de pandemia, así como para complementar el estudio de caso donde se evaluaron puntos relacionados con la citada enseñanza en las clases de Geografía en el periodo de febrero a marzo de 2021 en una escuela primaria privada. Los datos relacionados con el estudio de casos se describieron en forma de informe de experiencias. La conducción eficiente de la enseñanza de la Geografía siempre ha presentado dificultades, y en los análisis realizados durante las clases de esta ciencia, se destaca la falta de recursos suficientes para trabajar la ciencia geográfica en las clases de la escuela primaria, además de la dificultad para acompañar a los alumnos que asistían a las clases a distancia, principalmente en la articulación de las actividades que se aplicaban. Sin embargo, el escenario actual es sugestivo para la ciencia geográfica, que fue posible visualizar, especialmente en las clases impartidas en el $9^{\circ}$ grado, que tuvo una participación activa en las discusiones guiadas por el profesor, a través de la enseñanza del contenido sobre la Globalización y sus interpretaciones. Se considera que a pesar de las numerosas dificultades que se enfrentan en las clases de Geografía en la forma híbrida de enseñanza en el escenario actual, permitió su problematización, contribuyendo al conocimiento crítico y reflexivo sobre el medio ambiente por parte de los estudiantes.

Palabras clave: Educación Geográfica. Dificultades. Posibilidades. Aprendizaje. COVID-19. 


\section{INTRODUÇÃO}

A pandemia do COVID-19 não só desencadeou um problema de saúde pública como também de todas as áreas governamentais dos países do planeta, especialmente a economia e a educação. No contexto educacional, a pandemia levou ao fechamento de unidades escolares, as quais se viram diante da obrigação de adotarem novas medidas para dar continuidade ao processo de ensino-aprendizagem, como é o caso da aplicação de metodologias voltadas ao ensino remoto que se caracterizam pela utilização de tecnologias da informação e comunicação incluindo redes sociais, sites de reuniões, sites de questionários, cursos online, etc. (SENHORAS, 2020).

O processo de ensino-aprendizagem tornou-se mais complexo, pois novas variáveis foram envolvidas e com isso o surgimento de novas dificuldades como as limitações pessoais quanto à transmissão e absorção de conteúdos e dificuldades estruturais como as limitações quanto ao acesso ao ensino remoto (SENHORAS, 2020). Uma técnica relativamente nova de ensino no Brasil tem sido empregada como forma de suprir algumas das dificuldades encontradas no ensino totalmente remoto, que é o chamado ensino híbrido. É possível caracterizar o ensino de híbrido de diversas formas dependendo principalmente das características educacionais levadas em consideração. Contudo, neste trabalho o conceito de ensino híbrido é definido como

a combinação de atividades remotas com atividades realizadas na própria instituição de ensino onde os estudantes podem assistir presencialmente às aulas nas dependências da instituição ou podem acessá-las remotamente através de sessões de aulas online com o mesmo período de tempo ou com período de tempo diferente (THE UNIVERSITY OF EDINBURGH, 2020).

O ensino híbrido, apesar de manter um sistema em que as atividades escolares são articuladas tanto de forma presencial como remotamente, possui suas vantagens e suas desvantagens. Uma das principais vantagens é a flexibilidade das atividades, isso inclui as aulas, exercícios, avaliações, atividades práticas, etc. Neste sistema, é possível haver uma flexibilidade quanto aos horários, transporte e quanto a atividades que requerem a presença ou não dos estudantes. Além de que em aulas online os estudantes possuem mais facilidade em buscar informações, ler artigos, compartilhar informações e se comunicar com os colegas de classe e com os professores (COLLEGE OF DUPAGE, 2020).

Dentre as dificuldades encontradas no método de ensino híbrido pode-se citar o acesso às tecnologias tanto do seu ponto de vista econômico quanto mental. Do ponto de vista 
econômico, os estudantes e professores devem se adequar as novas metodologias de ensino remoto, utilizando computadores, tablets ou celulares capazes de acessar as suas atividades escolares, além da possibilidade de acesso à internet de qualidade necessária para o desenvolvimento das aulas. Do ponto de vista mental os estudantes e professores devem estar preparados para conseguir manipular, interagir e produzir conteúdos nos ambientes virtuais, possuindo certo nível de letramento digital para tanto (CASTRO, et al. 2015; ALVES, 2020).

De acordo com Alves (2020), existem também outras dificuldades relativas ao ensino híbrido, como o ambiente de estudo dos estudantes, em que muitos estudantes provenientes de famílias de classes sociais mais baixas, podem não possuir locais adequados para as aulas; complicações nos ambientes familiares; situação de estresse ou violência entre os membros da família; e a dificuldade dos pais em orientar os filhos nas atividades escolares, uma vez que muitas vezes os pais não estão em casa, ou não possuem o tempo necessário para auxiliar os filhos ou até mesmo por falta de conhecimento dos ambientes tecnológicos e virtuais.

A Geografia é uma das principais disciplinas da matriz curricular comum em todo o mundo ensinada nos três níveis de ensino, no caso brasileiro, o ensino fundamental, médio e superior, além de ser também disciplina obrigatória na Educação de Jovens e Adultos (EJA). A Geografia é essencial à construção da vida social humana, pois está presente em diversos setores de estudo, social, ambiental, físico-natural, cultural, político, econômico, dentre outros. Seu ensino proporciona a criação e aperfeiçoamento de elementos que são necessários ao desenvolvimento humano como o uso de elementos materiais para o auxílio em pesquisas, realização de pesquisas ou estudos práticos, elaboração de novas metodologias ou conceitos de tudo que faz parte do espaço geográfico (OLIVEIRA, 2021; RICHTER, 2011).

As mudanças no processo de ensino-aprendizagem durante a pandemia da COVID-19 têm afetado e continuam afetando as etapas desse processo, desde os elementos utilizados para conduzir as atividades até as novas metodologias de avaliação e ferramentas de uso de ambientes virtuais. A análise desse processo e dos seus elementos relativos ao ensino da Geografia dentro do contexto da pandemia ainda não foi devidamente explorado e constitui-se essencial, uma vez que pode contribuir aplicações de metodologias que facilitem e melhorem o ensino e a aprendizagem não só nas aulas de Geografia, mas também de outras disciplinas. Dessa forma, este trabalho objetiva-se em investigar os impasses e as perspectivas do ensino e das aulas de Geografia na modalidade híbrida de ensino mediante o contexto pandêmico atual. 


\section{METODOLOGIA}

Primeiramente fez-se necessária a realização de uma revisão bibliográfica para complementação do estudo de caso realizado nas aulas de Geografia, assim como quanto aos desafios do professor em empregar o saber cientifico nas aulas na modalidade remota de ensino e as dificuldades relativas à aplicação do ensino híbrido durante o contexto pandêmico. Para tanto, foram consultados artigos científicos de bancos de dados online como o Google Acadêmico, Scielo, Web of Science e MDPI, e sites de periódicos não vinculados a bancos de dados científicos, assim como informações provenientes de sites de instituições de ensino. A consulta de artigos e informações relevantes ao trabalho ocorreu durante o mês de março de 2021.

Foi realizado um estudo de caso no qual foram avaliados alguns pontos principais relativos ao ensino híbrido aplicado às aulas de Geografia durante o contexto da pandemia da COVID-19. Durante o estudo foram realizadas observações e análises ao decorrer das aulas de Geografia, as quais foram conduzidos durante o período de fevereiro a março de 2021 na Escola privada de ensino básico e fundamental Ágape na cidade de Pilar - Alagoas, na qual a principal autora atua como professora de Geografia. Nessas observações foram identificados e analisados aspectos relacionados a como os estudantes recebiam os conteúdos por meio da modalidade inicialmente remota e depois híbrida de ensino e como estes os interpretavam, os quais serviram de norte para a obtenção dos dados. Os dados referentes ao estudo de caso foram descritos sob forma de um relato de experiência enriquecido com informações bibliográficas, no qual foi destacado o contexto observado em sala de aula, as problemáticas, os fatores que norteiam o ensino híbrido de Geografia e suas respectivas estratégias de adaptação primordiais ao processo harmônico de ensino e aprendizagem num contexto pandêmico.

\section{RESULTADOS E DISCUSSÃO}

\section{Desafios do professor para desenvolver o saber científico no contexto da pandemia}

A educação brasileira atualmente vive um cenário sedento de motivação para a educação científica. Nessa perspectiva, a alfabetização científica apresenta um aparato de ferramentas que visam contribuir para a formação de capazes de atuar nas decisões do país utilizando conceitos científicos, assim como para direcionar àquilo que é estudado na escola, 
de modo que o ensino também possa ser utilizado pelo aluno em suas questões fora da escola e assim o mesmo possa aplicar os conceitos científicos no seu cotidiano social, cultural, econômico, etc. (SCHULZE; CAMARGO; WACHELKE, 2006).

Desse modo, a necessidade de uma educação científica se depara com o contexto atual de pandemia. O isolamento social junto às medidas de prevenção contra o vírus da COVID-19 provocou mudanças no modo do trabalho educacional. As modificações na forma como os professores estão realizando as aulas, sobretudo por meio do ensino remoto, e o uso dos dispositivos online, trouxeram implicações na aplicação dos indicadores da alfabetização científica, uma vez que, as práticas presenciais facilitavam o desenvolvimento de mecanismos mais eficazes na tarefa de ensinar o saber científico. No entanto, os indicadores da alfabetização científica, como a articulação de ideias, investigar, ler ciência, escrever ciência, criar, atuar, argumentar, podem ser desenvolvidos utilizando o mecanismo do ensino híbrido e até mesmo remoto, mas a tarefa de realizá-lo com a nova dinâmica virtual torna-se mais complicada (SCHWAN; MALESCZYK; WENZEL, 2017).

$\mathrm{Na}$ perspectiva dos indicadores de articulação de ideias e argumentação, pode-se verificar uma das barreiras mais complicadas encontradas pelos professores no ensino híbrido e/ou remoto: o diálogo com o aluno. Sabe-se que a comunicação entre aluno e professor tem um papel muito importante no ensino e a interação entre os participantes do processo educacional se faz necessária (NEVES, 2014). Verifica-se que alguns dos indicadores de alfabetização científica são prejudicados nesta nova realidade de ensino imposta pela pandemia, uma vez que a dinâmica do ensino híbrido ou totalmente remoto possui um contexto diferente do ambiente escolar, uma vez que as aulas no ensino remoto são compostas, muitas vezes, de estudantes que não se sentem à vontade para interagir, muitos não ligam a câmera, não opinam e não ativam o áudio, impossibilitando a interferência do professor sobre como o assunto está sendo recebido por eles. O ambiente escolar agora é o familiar e a forma como o aluno sente a pressão familiar pode influenciar durante as aulas.

Nesse sentido, todos esses fatores impactam a forma como o ensino está sendo passado e possíveis danos à educação científica podem ocorrer. A educação pública possui um alunado muitas vezes carente de recursos básicos, essenciais à sua qualidade de vida, de modo que o acesso à internet e a posse de aparelhos digitais torna-se realidade ilusória (ZAHER, 2020). Nesse contexto, a educação pública brasileira, a mesma que precisa fornecer uma educação de qualidade para mudar a realidade vivida por cidadãos carentes e a margem 
da sociedade, sofre com a realidade do ensino híbrido ou remoto, pois muitos estudantes ficam sem o acesso as aulas. Assim, os estudantes e, sobretudo o profissional da educação focado em mudar a realidade do ensino público através do ensino da alfabetização científica, é posto diante de inúmeras dificuldades, sejam por questões técnicas e/ou sociais.

\section{O ensino híbrido, recursos tecnológicos e os efeitos da pandemia sobre a educação}

No cenário pandêmico atual, novas formas e metodologias de ensino foram incrementadas ao cotidiano escolar, dentre elas destaca-se o ensino híbrido como abordagem metodológica para facilitar os conteúdos trabalhados pelos professores. O ensino híbrido pode ser considerado como uma mescla, combinação, mistura de inúmeros métodos, formas, jeitos e técnicas que podem conduzir o ensino de um determinado conteúdo (SCHIEHL; KEMCZINSKI; GASPARINI, 2017). Todavia, essa modalidade de ensino tem trazido sérias reflexões acerca do contexto social dos estudantes e professores que necessitam adotar esse tipo de abordagem em seu cotidiano para promover o processo de ensino e aprendizagem.

Os obstáculos a serem e quem vem sendo enfrentados, especialmente pelos estudantes e professores mais empobrecidos, muitos deles localizados na periferia das grandes cidades ou na zona rural, são inúmeros. Desprovidos de computadores, aparelhos de telefonia móvel, software e internet de boa qualidade, recursos imprescindíveis para atender a demanda estabelecida pelo ensino híbrido, sobretudo de forma emergencial, essa comunidade ver-se frente a uma gama de desafios e dificuldades, resultando em níveis elevados de ansiedade, de depressão e de estresse, maiormente provocados, também, pelo período de confinamento e quarentena que toda a população precisou enfrentar (MAIA; DIAS, 2020).

Sabe-se que os efeitos da pandemia não trouxeram muitas contribuições para a educação, ao contrário, ocorreu uma mudança significativa ao ponto de em algumas regiões não haver mais aulas e nenhum contato educacional, em função da precariedade infraestrutural. Dentre os efeitos críticos da pandemia da COVID-19 sobre a educação, destacam-se os impactos negativos manifestados pelo comprometimento do processo de ensino e aprendizagem e pelo aumento da evasão escolar, os quais demandaram ações estratégicas de curto prazo para a continuidade dos estudos, bem como o esforço de um planejamento de resolução de problemas para a normalização dos ciclos escolares no médio prazo (SENHORAS, 2020). 
A tecnologia ganhou bastante destaque nesse período de pandemia. Professores e estudantes incrementaram em seu cotidiano a tecnologia como forma de ensino e aprendizagem durante as aulas remotas. Assim, as novas tecnologias precisam ser aplicadas para que em tempo como o atual, a educação seja contínua e ininterrupta, levando ao desenvolvimento de aptidões dos estudantes brasileiros (ALMEIDA JÚNIOR et al., 2019). Um problema relacionado a essa questão diz respeito à baixa formação docente em manusear aparelhos tecnológicos, dificultando processo de ensino. Os estudantes e professores precisam familiarizar-se com as tecnologias existentes e desenvolver a capacidade de manipular, interagir e produzir conteúdo dentro do ambiente virtual para que as atividades interativas desenvolvidas na modalidade híbrida e remota de ensino sejam eficazes (CASTRO, et al., 2015).

\section{As aulas de Geografia na modalidade híbrida de ensino nas turmas do $6^{\circ}$ ao $9^{\circ}$ ano: 0 caso da escola Ágape (Pilar/Alagoas)}

Antes da pandemia da COVID-19, o ensino na maioria das escolas do Brasil era ofertado na sua forma presencial, contudo com o atual contexto pandêmico pelo qual o mundo está passando, necessitou-se buscar novas formas de continuar o processo de ensinoaprendizagem, o qual foi e tem sido desenvolvido tanto de forma totalmente remota, como de maneira híbrida. Nesse sentido, muitas escolas precisaram adaptar e desenvolver novas metodologias de ensino, o qual foi inicialmente de modo remoto, em que os professores ministram as aulas e acompanham os estudantes, de forma síncrona ou assíncrona, sem o auxílio de tutores como ocorre no EAD. Foi dessa maneira que ocorreu com a escola de ensino privado básico e fundamental Ágape, situada no município de Pilar, no estado de Alagoas.

No ano vigente, as aulas na escola Ágape foram retomadas de forma híbrida, seguindo todas as restrições sanitárias impostas, depois de um ano letivo em que as aulas foram totalmente ministradas na modalidade remota de ensino. Juntamente com o retorno híbrido das aulas, acompanharam os novos desafios, e consequentemente a busca por meios mais eficazes de propiciar o ensino, agora de forma ainda mais substancial. Mediante esse contexto, começou-se a pensar e desenvolver maneiras de melhor conduzir o ensino, especialmente o ensino geográfico nas aulas de Geografia, o qual é componente curricular obrigatório nos anos finais do ensino fundamental, assim como do ensino médio e da educação de jovens e adultos (OLIVEIRA, 2021). 
Mediante esse contexto, é imprescindível ressaltar que o ensino de Geografia, realizado, efetivado e construído no ambiente escolar, "marcado pela presença de importantes debates em sala de aula, uso de elementos característicos como mapas e globos, realização de saídas de estudos para trabalhos de campo", entre outros elementos, é essencial para a vida de todo e qualquer cidadão (OLIVEIRA, 2021, p. 1). Assim, em tempos de pandemia, o ensino de Geografia, considerando-se o objeto de estudo da ciência geográfica, que é o espaço geográfico, compreendido como "um conjunto indissociável de sistema de ações e sistemas de objetos”, conforme enfatizado por Santos (1997, p. 32, 1996), as suas categorias de análise, lugar, território, região e paisagem, reforça de forma ainda mais cuidadosa a necessidade de novas possibilidades analíticas acerca dessas categorias e na forma como elas devem ser analisadas.

Inicialmente, a gestão da escola em questão, depois de realizadas reuniões junto ao corpo docente, discutiu a respeito do ensino híbrido no intuito de orientar aos docentes acerca dessa nova modalidade que seria adotada pela escola. Em seguida, o que fora pautado em reunião, foi repassado a toda comunidade envolvida à escola, pais e estudantes, por meio de grupos no WhatsApp, a qual foi orientada quanto ao retorno das aulas na sua forma híbrida. Cada turma do ensino fundamental II da referida escola, sendo quatro turmas, $6^{\circ}, 7^{\circ}, 8^{\circ}$ e $9^{\circ}$ ano respectivamente, foi divida de maneira que os estudantes de cada turma fossem para a escola em dias alternados, para evitar aglomerações e consequentemente a propagação do vírus da COVID-19, e assim preservar a saúde pública.

Todas as salas de aulas foram adaptadas para receber os estudantes de modo a não aglomerar e garantir o controle, de maneira que as cadeiras foram separadas umas das outras, marcadas com uma fita adesiva vermelha, indicando que os estudantes não poderiam sentar nestas (Figuras 1 e 2). Enquanto uma parte de cada turma teria que assistir as aulas em casa, as quais estão sendo transmitidas pelos professores na própria escola, através do Google Meet, conforme determinado pela gestão da escola, a outra parte assistiria essas aulas de maneira presencial, ou seja, ambas as partes das turmas assistem as aulas no mesmo horário. 
Figuras 1 e 2: Sala de aula com cadeiras separadas e demarcadas com fita adesiva.

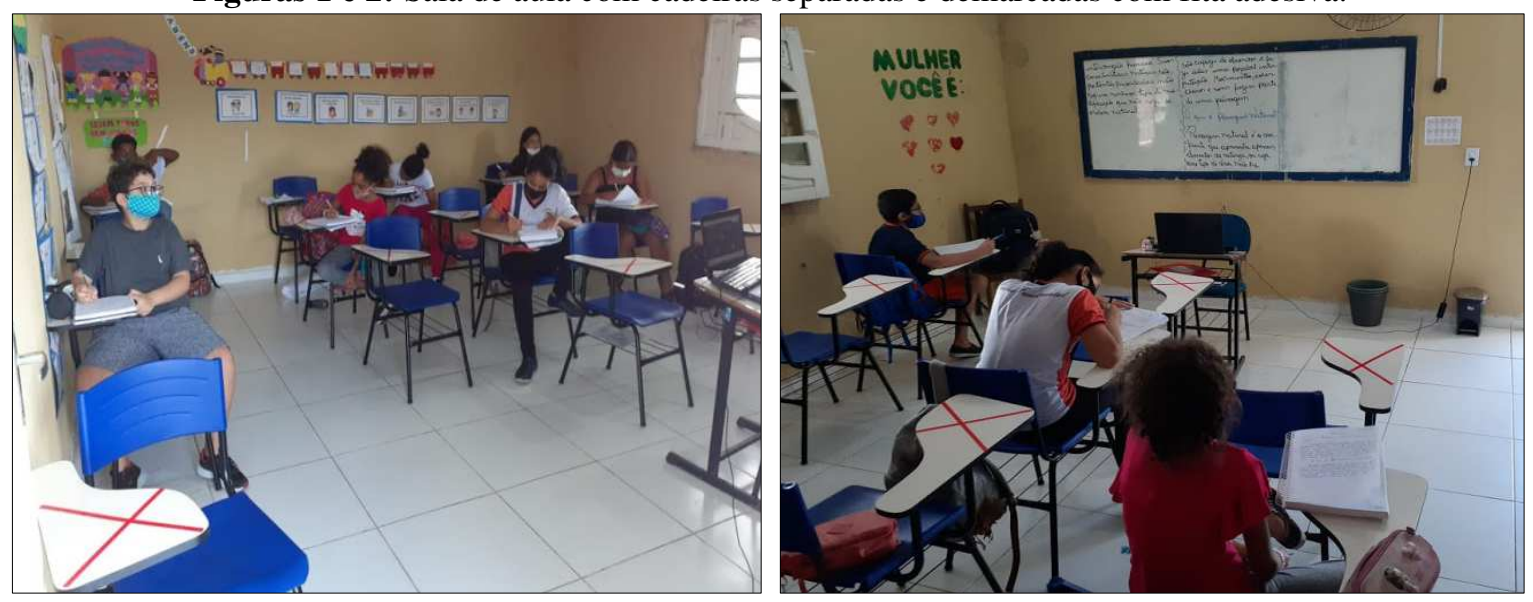

Fonte: Arquivo próprio (2021).

Nesse contexto, as aulas de Geografia foram conduzidas seguindo as novas normas estabelecidas, na sua modalidade híbrida. Assim, a priori, a turma do $7^{\circ}$ ano, composta de 25 estudantes, foi dividida de maneira que uma parte assistia as aulas na própria sala juntamente com o professor que transmitia a aula por meio de um celular num suporte de tripé, através da plataforma Microsoft Teams, a qual era retroprojetada para a outra parte da turma que assistia a aula na sala de vídeo da escola. Dessa forma, após o novo decreto, a sala de vídeo foi fechada e a parte da turma do $7^{\circ}$ ano que assistia as aulas nesta sala também passou a assistir as aulas em casa, conforme as demais turmas do ensino fundamental.

Além da utilização de materiais comuns a qualquer disciplina, como o livro didático e a lousa, foram realizadas algumas adaptações na forma de como as aulas de Geografia agora teriam que ser ministradas, de maneira a não afetar o processo de aprendizagem dos estudantes. O notebook que antes era utilizado para transmitir os slides preparados para a aula, retroprojetados, agora é utilizado para o acesso à plataforma do Google Meet, para atender a parte da turma que estava em casa, conforme Figuras 3 e 4 . Por falta de outros recursos e com problemas de conexão frequente com a internet, não era possível transmitir os slides para todos os estudantes ao mesmo tempo em que ministrava a aula na plataforma. Nesse sentido, os conteúdos escritos na lousa eram enviados para o grupo da turma no WhatsApp para que os que estavam em casa também pudessem escrever, e em seguida todos participavam da explicação. 
Figuras 3 e 4: Notebook utilizado para transmissão das aulas na plataforma do Google Meet.
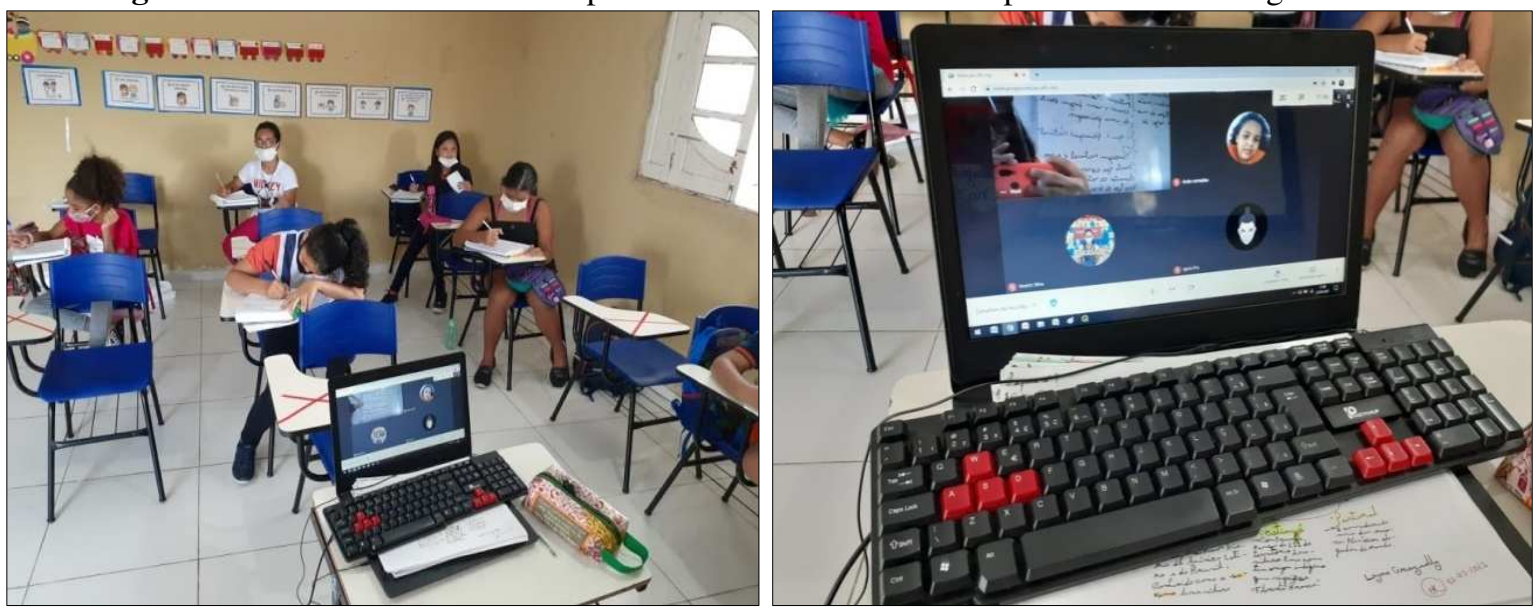

Fonte: Arquivo próprio (2021).

Marcado por intensos debates, sobretudo quanto ao processo de aprendizagem, o ensino de Geografia e a sua condução de forma eficiente sempre apresentou dificuldades, as quais caminham para além da falta de meios eficazes para o desenvolvimento das aulas, embora dentre as principais dificuldades sentidas antes e durante a ministração das aulas de Geografia na escola Ágape, destacam-se a falta de recursos considerados como suficientes para se trabalhar a ciência geográfica nas turmas do ensino fundamental, além da dificuldade de acompanhar os estudantes que estavam assistindo a aula de forma remota, principalmente na condução e articulação das atividades que eram aplicadas. É válido destacar a necessidade da metodologia voltada às novas tecnologias, assim como a qualificação do profissional para atuar na disciplina Geografia “já que se buscou compreender as relações que se estabelecem entre o homem e o meio natural que no mesmo habita ao longo da história em diferentes espaços e lugares" (SOUSA; BARBOSA; LINS, 2018, p. 1).

Nesse contexto, é válido enfatizar que o ensino de Geografia, desenvolvido através das aulas mediadas por um professor da disciplina, sobretudo na educação básica, constitui-se como essencial para a formação do pensamento crítico, assim como da cosmovisão do aluno, de modo que este se torna capaz de compreender e interpretar a dinamicidade e espacialidade do mundo no qual ele estar inserido. No cenário pandêmico vigente, o ensino de Geografia dá a possibilidade de se compreender o processo que envolve a situação atual do mundo, pois engloba questões que a ciência geográfica preocupa-se em entender, uma vez que de acordo com Cavalcanti (2014), o ensino de Geografia visa, também, gerar contribuições que proporcionem aos estudantes o pensar de modo espacial. 
Decerto, é possível afirmar que o ensino remoto, que de acordo com Ferreira e Tonini (2020) é uma forma de suprir uma parte do currículo e até mesmo preservar a relação dos estudantes com a escola, não possibilita a articulação do ensino de Geografia de forma eficiente, assim como de qualquer outra disciplina, se não houver um planejamento adequado para tal, uma vez que este configurou-se de maneira emergencial, e como outrora ressaltado, foi também adotado inicialmente pela escola em questão. Diante disso, fez-se necessário pensar como a demanda surgida com a pandemia seria atendida e como importantes temas de cunho especialmente geográfico deveriam ser trabalhados agora na modalidade híbrida de ensino, inicialmente por meio do ensino remoto.

Destaca-se o estudo conduzido por Carvalho Filho e Gengnagel (2020) em escolas do ensino Médio de Ribeirão Preto - SP e Passo Fundo - RS, no qual os autores destacam que o ensino de Geografia em sala no contexto da pandemia teve mudanças que afetaram diretamente a forma como as atividades foram conduzidas pelos professores e estudantes, com a utilização de ambientes virtuais que, com o passar dos dias, tornaram-se ferramentas de planejamento de aulas, debates e promoção do ensino da Geografia crítico-reflexiva que, de acordo com Freire (2002), é o tipo de ensino o qual tem o aluno como sujeito na construção do conhecimento.

Todavia, apesar de todas essas dificuldades, mediante a necessidade de uma ressignificação do ensino, o contexto pandêmico atual é sugestivo à ciência geográfica, sobretudo à Geografia escolar, o que foi possível visualizar nas aulas da turma do $9^{\circ}$ ano, a qual teve participação ativa nas discussões orientadas pela professora, tanto os que estavam na sala presencial como na virtual, por meio da ministração do conteúdo programático inicial acerca da Globalização e as suas interpretações. Questões relacionadas à desigualdade econômica e social e aos direitos sociais também foram levantadas durante as aulas, de maneira que foi possível problematizar e relacionar com o contexto atual que a sociedade encontra-se, na qual os estudantes estão inclusos, por meio de uma análise espacial, possibilitando-os a pensar de forma crítica e reflexiva sobre o seu espaço vivido, as transformações socioambientais e econômicas, as funções e posicionamentos políticos, e as influências dessa situação em seu cotidiano. 


\section{CONSIDERAÇÕES FINAIS}

Mediante o que fora exposto no presente artigo, pode-se considerar que apesar das desvantagens terem, aparentemente, um peso maior do que as vantagens quanto ao ensino híbrido, ressalta-se que dentro do atual contexto pandêmico a forma de ensino híbrida tornouse essencial e necessária, uma vez que a própria lógica, além do contexto científico, nos mostra que tal ferramenta contribui com a diminuição da proliferação da COVID-19, evitando o contato demasiado e por longos períodos de tempo entre os estudantes e professores nas salas de aulas durante as atividades. Todavia, percebe-se que as novas formas de levar o ensino precisam avaliar como contornar as dificuldades existentes na realidade educacional.

As aulas de Geografia na modalidade híbrida de ensino possuem suas interfaces, compostas de inúmeros desafios, que envolvem desde a ausência de recursos e materiais de apoio para facilitar a dinamização das aulas e a aprendizagem por parte dos estudantes até a falta de meios para se adaptar as mudanças, que envolvem fatores socioeconômicos, e possibilidades, uma vez que o cenário atual é sugestivo à ciência geográfica, de maneira a contribuir para o conhecimento crítico e reflexivo acerca do meio. A partir disso, percebe-se a necessidade de professores e estudantes se adaptarem as novas formas de ensino e aprendizagem mediante o contexto que a pandemia trouxe para a sociedade brasileira.

Diante disso, é importante ressaltar que apesar dos problemas estruturais configurados em muitas escolas do Brasil, o ambiente escolar se estabelece como imprescindível e principal no que diz respeito o processo da formação intelectual e social da comunidade que nela esteja inserida, pois é a partir e durante tal processo que é possível estabelecer fundamentais relações e promoção de conhecimentos que contribuam, em larga ou em estreita escala, para o desenvolvimento progressivo da sociedade. Partindo de uma análise pertinente à Geografia, pode-se considerar que é através do ensino da ciência geográfica que o aluno se torna apto a ler, compreender, interpretar de maneira espacial o meio que ele faz parte e é agente transformador, especialmente no contexto pandêmico atual. 


\section{REFERÊNCIAS}

ALMEIDA JÚNIOR, S. et al. Bases pedagógicas em curso profissionalizante de farmácia e laboratório clínico como apoio na construção profissional do indivíduo. Revista Eletrônica Acervo Saúde, São Paulo, v. 25, n. 1, p. 1- 6, 2019.

ALVES, L. Educação remota: entre a ilusão e a realidade. Interfaces científicas, Aracaju, v.8, n.3, p. 348-365, 2020.

CARVALHO FILHO, O. R.; GENGNAGEL, C. L. Ensino de Geografia em tempos da Covid-19: tecnologias e uso de plataformas de educação para o ensino remoto em Ribeirão Preto/SP e em Passo Fundo/RS. Ensaios de Geografia, Rio de Janeiro, v. 1, n. 1, p. 1-5, 2020.

CASTRO, E. A. et al. Ensino híbrido: desafio da contemporaneidade? Periódico Científico Projeção e Docência, Taguatinga, v.6, n.2, p. 47 - 58, 2015.

CAVALCANTI, L. de S. A Metrópole Em Foco No Ensino De Geografia: o que/para que/para quem ensinar? In: PAULA, F. M. A.; SOUZA, V. C.; CAVALCANTI, L. S. (Orgs.). Ensino de Geografia e metrópole. 1.ed. Goiânia: Gráfica e Editora América, 2014.

COLLEGE OF DUPAGE. An introduction to hybrid teaching. [S.I]: College of Dupage, 2020. Disponível em: https://www.codlearningtech.org/PDF/hybridteachingworkbook.pdf. Acesso em: 21 de mar. 2021.

FERREIRA, D. S; TONINI, I M. Há uma escola como lugar em período de pandemia? Ensaios de geografia, Niterói, v. 5, n. 10, p. 27 - 32, 2020.

FREIRE, P. Pedagogia da autonomia: saberes necessários à prática educativa. 25 ed. Rio de Janeiro: Paz e Terra, 2002, 144 p.

MAIA, B. R.; DIAS, P. C. Ansiedade, depressão e estresse em estudantes universitários: o impacto da COVID-19. Estudos de Psicologia, Campinas, v. 37, n. 1, p. 1- 8, 2020.

NEVES, C. S. B. As relações de interação e diálogo como meio de favorecer a aprendizagem. 2014. 20 f. Especialização - Curso de Especialização em Coordenação Pedagógica, Setor de Educação, Universidade Federal do Paraná, Curitiba, 2014.

OLIVEIRA, V. H. N. Como fica o ensino de Geografia em tempos de pandemia da Covid-19? Ensino em Perspectivas, Fortaleza, v. 2, n. 1, p. 1-15, 2021.

RICHTER, D. O mapa mental do ensino de geografia: concepções e propostas para o trabalho docente. 1. ed. São Paulo: Cultura Acadêmica, 2011, 270 p.

SANTOS, M. A Natureza do Espaço: técnica e tempo, razão e emoção. 1. ed. São Paulo: Hucitec, 1996. 388p. 
SCHIEHL, E. P; KEMCZINSKI, A; GASPARINI, I. As Perspectivas de Avaliar o Estudante no Ensino Híbrido. Revista Novas Tecnologias na Educação, Porto Alegre, v. 15, n. 2, p. 1 $-10,2017$.

SCHULZE, C. N.; CAMARGO, B.; WACHELKE, J. Alfabetização científica e representações sociais de estudantes de ensino médio sobre ciência e tecnologia. Arq. bras. psicol., v. 58, ed. 2, 2006.

SCHWAN, F.; MALESCZYK, C. R.; WENZEL, J. S. A importância da alfabetização científica no ensino de ciências e química. In: $37^{\circ}$ ENCONTRO DE DEBATES SOBRE O ENSINO DE QUÍMICA, 37, 2017, Carreiros. Anais... Carreiros: [s. I], 2017, p. 1 - 6.

SENHORAS, E. M. Coronavírus e educação: análise dos impactos assimétricos. Boletim de Conjuntura, Boa Vista, v.2, n.5, p. 128 - 136, 2020.

SOUSA, A. C.; BARBOSA, J. R. P.; LINS, C. S. Os desafios e as dificuldades encontradas na disciplina de Geografia no $6^{\circ}$ ano do Ensino Fundamental da Escola Municipal Dr. Antonio Regis, município de Miguel Alves (PI). Revista Científica Multidisciplinar Núcleo do Conhecimento, [s. I.], v. 12, n. 8, p. 05-17, 2018.

THE UNIVERSITY OF EDINBURGH. What is hybrid teaching? [S.I]: The University of Edinburgh, 2020. Disponível em: https://www.ed.ac.uk/information-services/learningtechnology/more/teaching-continuity/teaching-continuity-overview. Acesso em: 21 de mar. 2021.

ZAHER, C. O vírus da desigualdade na educação. Veja, [s. I.], p. 5-7, 29 jun. 2020. 